\title{
Refractive behavior changes with six months daily wear of high and low oxygen permeability hydrogel contact lenses
}

\section{WDH Gillan*}

Optometric Science Research Group, Department of Optometry, University of Johannesburg, PO Box 524, Auckland Park, 2006 South Africa

<wdhg@na.rau.ac.za >

\begin{abstract}
Introduction: The investigation of myopia and soft contact lenses is not new. Many reports show that the wearing of silicone hydrogel lenses as opposed to conventional disposable hydrogel lenses results in little progression of myopia in the eyes wearing silicone hydrogels.

Method: Six subjects wore a silicone hydrogel lens on one eye while the other eye wore a habitual disposable hydrogel lens for six months of daily wear. Fifty measurements of refractive state in each eye were taken prior to the subjects wearing a silicone lens in one eye and a conventional hydrogel lens in the other eye. After six months of daily wear another fifty measurements of refractive state were taken for each subject.

Results: Although there is no statistical support for the findings of this study, comet stereo-pairs are used to show the changes in refractive state for each subject. Four of the six subjects showed an increase in myopia in the eye wearing the silicone lens.

Discussion: The increase in myopia in eyes wearing a silicone hydrogel lens is contrary to the findings of other studies.
\end{abstract}

\section{Introduction}

Myopia, its development and progression has received a lot of attention recently ${ }^{1-7}$. Studies investigating myopia and; susceptibility to nearwork demands ${ }^{8}$, occupation ${ }^{9}$, reading ${ }^{10}$, and genetics ${ }^{11}$ have been published. The progression of myopia induced by the daily wear of hydrogel contact lenses has also been investigated ${ }^{12-15}$ where it was found that a small increase in myopia occurs during the initial phases of hydrogel contact lens wear. These myopic changes have generally been attributed to the development of corneal oedema associated with hydrogel contact lens wear ${ }^{16-18}$. Fulk ${ }^{19}$ et al have shown that children who switched from wearing spectacles to soft contact lenses manifested an increased rate of myopia progression that was three times faster than those children who retained their spectacles. Douthwaite, Ford and Stone ${ }^{20}$, however, state that hydrogel lenses have little effect on the refractive state of the eye due to the uniform nature of the swelling across the whole cornea. Bruce and Brennan ${ }^{21}$ suggest that little change in refractive state occurs in association with corneal oedema that has a uniform area of greater than $8 \mathrm{~mm}$ in diameter. Efron and Fitzgerald ${ }^{22}$, however, have shown that corneal oxygenation is dependent on the lens thickness profile. What effects might the differential supply of oxygen to the cornea, induced by a negative-power hydrogel contact lens, have on the topography of the cornea? Gillan ${ }^{23}$ published an anecdotal account of two patients who terminated hydrogel contact lens wear for more than 18 months who then presented with an, extreme, reduction in myopia. Dumbleton et a ${ }^{24}$ have shown that continuous wear of high oxygen permeable silicone hydrogel lenses has no impact on refractive state

*DipOptom DPhil(RAU) CAS(NewEnCO) FAAO FIACLE

Received 5 April 2006; revised version accepted 26 June 2006 
compared with low oxygen permeable hydrogel lenses when worn over a nine month period. They showed that there was an increase in myopia in the subjects who were wearing low-Dk lenses $(-0.30 \pm 0.45 \mathrm{D})$. Long et a ${ }^{25}$, investigating refractive changes in subjects wearing silicone lenses for three years, found that there was little increase in myopia over their study period and support the finding of Dumbleton and co-workers ${ }^{24}$. A four month randomized study conducted by Fonn et $a l^{26}$ found a significant increase in myopia in eyes wearing low Dk lenses while eyes wearing high Dk silicone hydrogel lenses showed an insignificant increase in myopia. A study conducted by Jalbert et $a l^{27}$ also revealed an increase in myopia in subjects wearing low DK lenses. Subjects wearing high Dk lenses revealed a regression in myopia. I am not aware of any studies investigating the effects of daily wear of silicone hydrogels versus low-Dk hydrogel lenses on myopic change. This study was conducted to investigate changes in refractive behavior induced by low and high oxygen permeable contact lenses worn on a daily-wear basis for six months.

\section{Method}

Nine fourth-year optometry students (average age: 22 years) in the Department of Optometry at the Rand Afrikaans University volunteered as potential subjects for this study. The study protocol was explained to them and they gave their informed consent to be included in the study. All subjects were treated according to the tenets of the Declaration of Helsinki. All subjects were screened prior to inclusion in the study. All subjects had to be habitual daily wearers of spherical, disposable hydrogel (not including silicone hydrogels) contact lenses who had been wearing lenses for a minimum of two years. Subjects had to have an aided habitual VA of 6/6 (20/20) or better. All habitual lenses had to fit adequately (according to usual clinical criteria) and induce no striae, folds, staining or obvious microcystic oedema. It should be noted that all subjects, with the exception of subject 3 , had neovascularization. Each subject presented for the initial measurements of refractive state wearing their habitual lenses. The habitual lenses were removed and 50 autorefractor measurements of refractive state of each eye were taken using a Nidek ARK-700 autorefractor. The autorefractor was refocused after each measurement and measured refractive state in $0.01 \mathrm{D}$ and 1 degree increments. A print-out was made after each set of ten measurements. The use of an autorefractor to take multiple measurements of refractive state and the accuracy of autorefractors has been well documented in the literature $^{28-31}$. The protocol of the study required that each subject wear their habitual lens (excluding silicone hydrogel lenses) on one eye and a silicone (lotrafilcon A) hydrogel lens on the other eye (see Table 1 for silicone lens parameters). The eye to wear the silicone hydrogel lens was decided by means of a coin toss. Trial lenses were inserted and after 20 minutes the fit of the lenses was assessed. The silicone hydrogel lenses fit all nine subjects well, according to normal clinical criteria. A box of six silicone lenses was dispensed to all nine subjects with the instructions that they had to wear the silicone lens on the chosen eye and their habitual lens on the remaining eye for six months of daily wear, disposing of each lens at monthly intervals. Three of the nine subjects experienced unacceptable discomfort when wearing the silicone hydrogel lenses and chose to terminate their participation in the study. Of the remaining six subjects five were female. Table 2 gives the parameters of the habitual lenses that each remaining subject was wearing prior to the dispensing of the silicone hydrogel lenses. Subject compliance, comfort and corneal health were monitored at regular intervals during the six month duration of the study. Following six months of daily silicone and conventional hydrogel lens wear the subjects returned when a further 50 autorefractor measurements of refractive state of each eye were taken. The eye wearing the habitual hydrogel lens acted as a control. Autorefractor measurements were converted and analyzed making use of methods developed by Harris and used extensively by the Optometric Science Research Group ${ }^{32-37}$ (for a complete exposition of the methods used in this study see Harris $^{38-42}$ ). Briefly each autorefractor measurement, consisting of sphere, cylinder and axis, is 


\begin{tabular}{|l|l|}
\hline \multicolumn{2}{|l|}{ Table 1: Silicone hydrogel lens (Lotrafilcon A) parameters } \\
\hline Material & Lotrafilcon A \\
\hline Water content & $24 \%$ \\
\hline DK $($ Barrer $)$ & $140 \times 10^{-11}$ \\
\hline DK/t $\left(\mathrm{ccO}_{2} \mathrm{sec}-^{-1} \mathrm{~cm}^{-2} \mathrm{mmHg}^{-1}\right.$ & $175 \times 10^{-9}$ \\
\hline Base Curve $(\mathrm{mm})$ & 8.6 \\
\hline Diameter $(\mathrm{mm})$ & 14.0 \\
\hline
\end{tabular}

Table 2: Subject's habitual lens parameters

\begin{tabular}{|l|l|l|l|l|}
\hline Subject & Lens & $\begin{array}{l}\text { Base curve } \\
(\mathrm{mm})\end{array}$ & $\begin{array}{l}\text { Water } \\
\text { content }\end{array}$ & $\begin{array}{l}\text { DK/t } \\
\left(\mathrm{x} \mathrm{10} 0^{-9}\right)\end{array}$ \\
\hline 1 & Focus visitint & 8.9 & $55 \%$ & 20 \\
\hline 2 & Actifresh 400 & 8.8 & $73 \%$ & 30 \\
\hline 3 & Actifresh 400 & 8.8 & $73 \%$ & 30 \\
\hline 4 & Focus visitint & 8.6 & $55 \%$ & 20 \\
\hline 5 & $\begin{array}{l}\text { Proclear } \\
\text { compatible }\end{array}$ & 8.6 & $62 \%$ & 41.5 \\
\hline 6 & $\begin{array}{l}\text { Proclear } \\
\text { compatible }\end{array}$ & 8.6 & $62 \%$ & 41.5 \\
\hline
\end{tabular}

converted into three coordinates (stigmatic, ortho-antistigmatic and oblique anti-stigmatic) of a sub-space known as symmetric dioptric power space. The three components give a complete representation of the three-dimensional character of dioptric power. It is not necessary to limit analysis to only the spherical or cylindrical components of refractive state or to use equivalent sphere as other researchers have done ${ }^{24-26}$ when making use of the coordinates in symmetric dioptric power space. Once the three coordinates of each measurement of refractive state have been calculated it is possible to determine a mean refractive state that is complete $^{38,39}$, variance and covariance of the data ${ }^{38}$, conduct hypothesis tests ${ }^{40}$ and present findings by means of three-dimensional stereo-pairs ${ }^{41}$.

\section{Results}

Before presenting the results of this study it needs to be stated that the findings shown here have no statistical support... the findings could be purely as a result of chance. This results from the small subject base. Nevertheless, the results of the study will be presented here, for various reasons. The results of each subject are going to be shown individually making use of three-dimensional scatter plots. Each scatter plot shows the mean of fifty measurements before and after the wearing of a lens for six months (including a 95\% confidence ellipsoid around each mean). What each scatter plot shows is a pure representation of the data with no assumptions of normality or equivalence of variance needed. Each scatter plot shows the means of the data as they were recorded, in symmetric dioptric power space. The methods used to convert, analyze and present the refractive state data have not been used when dealing with contact lens related data before (as far as I am aware). This article will show that there are individuals, who when wearing a silicone hydrogel lens on one eye, reveal an increase in myopia in that eye, a finding that is contrary to the findings of other researchers.

Figure 1 shows the means of the data collected for subject 1 connected by a line (called a comet) extending from the mean of the initial set of measurements (shown by an asterisk) to the mean of the measurements taken after six months (a dot). The red comet represents the eye wearing the habitual hydrogel lens for the six months and the green comet represents the eye wearing the silicone hydrogel lens. Each mean is surrounded by a $95 \%$ confidence ellipsoid. The ellipsoids of some means are tiny and are difficult to make out. The length of each axis of the scatter plots is $1 \mathrm{D}$ with tick intervals of 0.25 D. The I axis represents the stigmatic (spherical) component of refractive state with the less negative half of the stigmatic axis being shown in each scatter plot. This applies to all figures in this article. The origin of the axes in Figure 1 is -3.50 D. Figure 1 shows that both eyes had a mainly hyperopic shift (less myopia) in refractive state over the six months of the study period, shown by the "upward" movement of the comet from the asterisk to the dot (or from the mean of data taken before the study commenced to the mean of data collected after six months of lens wear). The means for each set of measurements can be seen in Table 3 with the differences between the means being shown in Table 4 .

Subject 2 is represented in Figure 2. The origin of the axes is $-2.50 \mathrm{D}$. A small hyperopic shift is seen in the red comet, an indication that the eye wearing the habitual lens underwent little change in refractive state over the six months of the study. The green comet, on the other hand, shows that a larger, and mostly, hyperopic shift occurred in the eye wearing the silicone hydrogel lens. Tables 3 and 4 show the means, and differences between the means, of the data, respectively.

The origin of the axes in Figure 3 is $-3.00 \mathrm{D}$. Subject 3 is represented here. Both eyes show a 

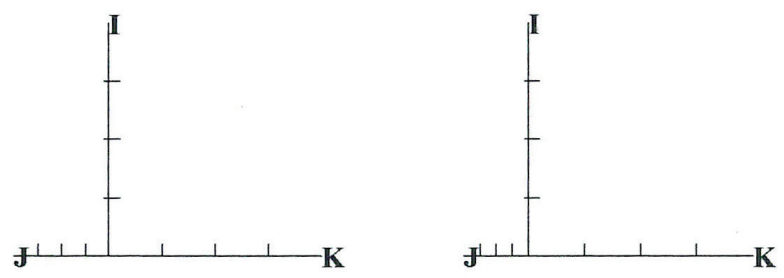

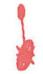

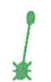

Figure 1. A comet stereo-pair for subject 1 is shown. The red data shows the comet for data collected from the eye wearing the habitual lens while the green data represents the eye wearing the silicone hydrogel. The asterisk represents the mean of fifty measurements taken before the lenses were worn and the dot the data collected after six months of wear. A 95\% confidence ellipsoid surrounds each asterisk and dot, this applies to all the stereo-pairs in this article. The origin of the axes is $-3.50 \mathrm{D}$. A reduction in myopia is shown in each eye.

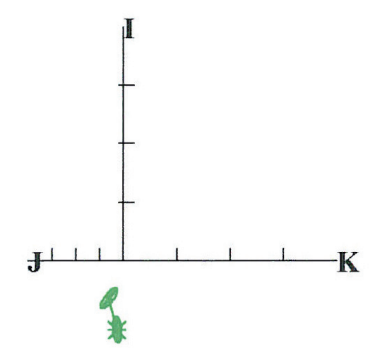

(3)

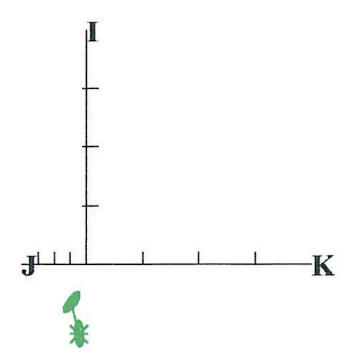

1
Figure 2. A comet stereo-pair for subject 2 is shown. The origin of the axes is $-2.50 \mathrm{D}$. A reduction in myopia is shown in each eye with the eye wearing the silicone lens showing the greatest hyperopic shift.
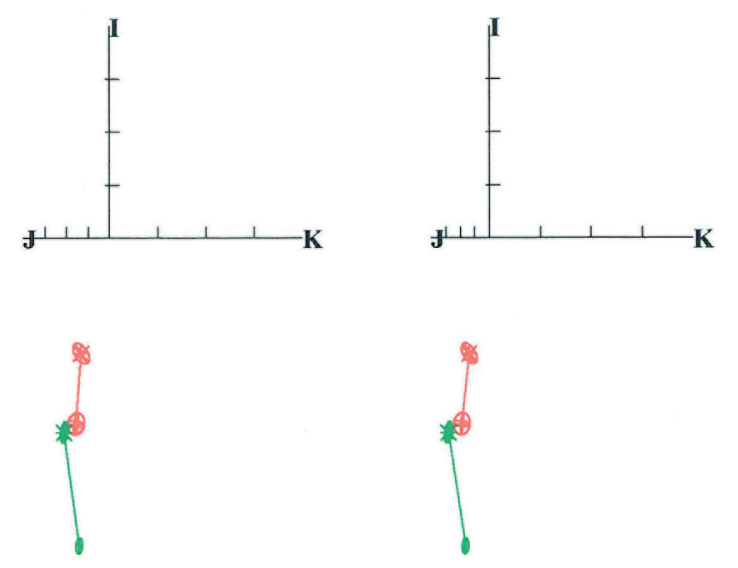

Figure 3. A comet stereo-pair for subject 3 is shown. The origin of the axes is $-3.00 \mathrm{D}$. An increase in myopia is seen in both eyes. The eye wearing the silicone lens (green data) reveals the larger myopic shift.

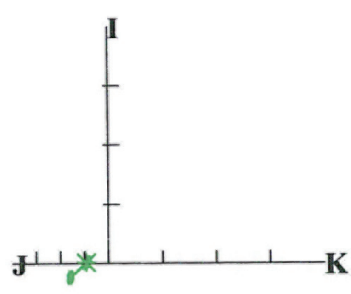

-

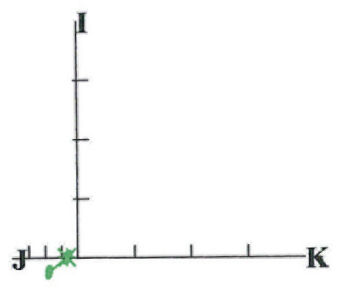

-
Figure 4. A comet stereo-pair for subject 4 is shown. The origin of the axes is $-4.00 \mathrm{D}$. Although little change is seen in either eye, the eye wearing the silicone lens shows a small increase in myopia while the habitual lens wearing eye shows a small decrease in myopia.
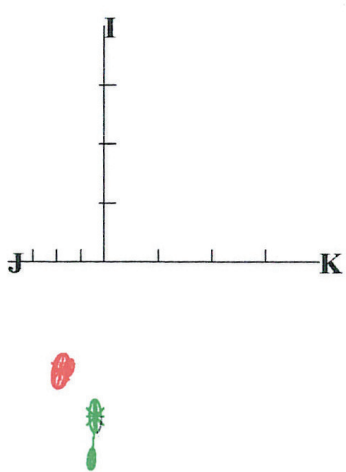
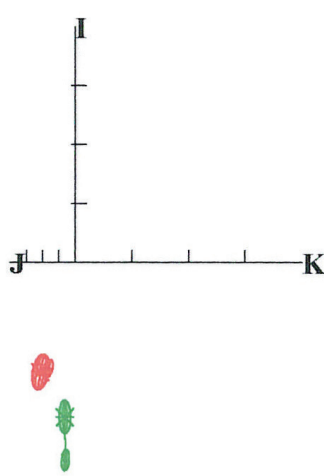

Figure 5. A comet stereo-pair for subject 5 is shown. The origin of the axes is $-2.00 \mathrm{D}$. Little change is seen in the eye wearing the habitual lens (red data) with the silicone lens wearing eye showing an increase in myopia.
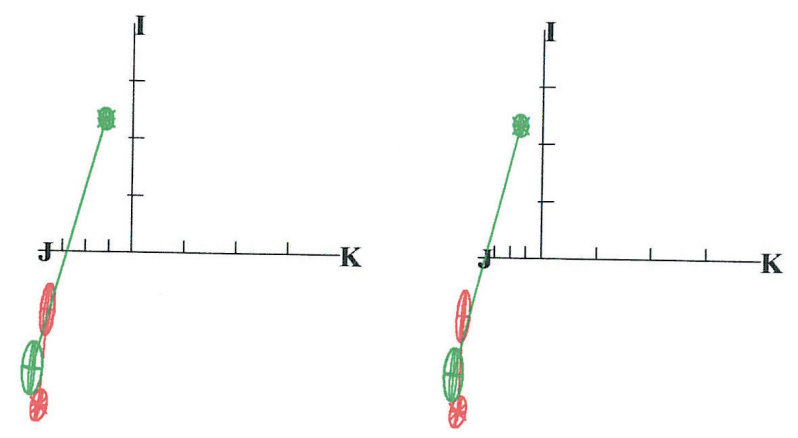

Figure 6. A comet stereo-pair for subject 6 is shown. The origin of the axes is $-5.00 \mathrm{D}$. A large shift (an increase in myopia,) is seen in the green data (silicone lens wearing eye). The eye wearing the habitual lens shows a decrease in myopia (hyperopic increase). 


\begin{tabular}{|c|c|c|c|c|c|c|c|}
\hline Subject & Control / Experiment & \multicolumn{3}{|c|}{ Conventional notation } & \multicolumn{2}{|c|}{ Component notation } & $\mathrm{Fob}$ \\
\hline \multirow[t]{4}{*}{1} & $\mathrm{Cb}$ & -3.50 & -1.10 & x 174 & -4.06 & 0.54 & -0.11 \\
\hline & $\mathrm{Ca}$ & -3.39 & -0.96 & × 169 & -3.87 & 0.45 & -0.17 \\
\hline & $\mathrm{Eb}$ & -4.19 & -0.90 & x 1 & -4.64 & 0.45 & 0.01 \\
\hline & $\mathrm{Ea}$ & -4.05 & -0.60 & x 179 & -4.35 & 0.30 & -0.02 \\
\hline \multirow[t]{4}{*}{2} & $\mathrm{Cb}$ & -2.97 & -0.49 & × 87 & -3.21 & -0.24 & 0.03 \\
\hline & $\mathrm{Ca}$ & -3.00 & -0.33 & x 83 & -3.17 & -0.16 & 0.04 \\
\hline & $\mathrm{Eb}$ & -2.76 & -0.06 & × 129 & -2.80 & -0.01 & -0.03 \\
\hline & $\mathrm{Ea}$ & -2.60 & -0.12 & x 143 & -2.66 & 0.02 & -0.0 \\
\hline \multirow[t]{4}{*}{3} & $\mathrm{Cb}$ & -3.25 & -0.59 & x 179 & -3.55 & 0.29 & -0.01 \\
\hline & $\mathrm{Ca}$ & -3.64 & -0.47 & x 171 & -3.88 & 0.22 & -0.07 \\
\hline & $\mathrm{Eb}$ & -3.67 & -0.49 & x 161 & -3.92 & 0.19 & -0.15 \\
\hline & $\mathrm{Ea}$ & -4.21 & -0.49 & x 174 & -4.45 & 0.23 & -0.05 \\
\hline \multirow[t]{4}{*}{4} & $\mathrm{Cb}$ & -4.40 & -0.38 & x 16 & -4.59 & 0.16 & 0.10 \\
\hline & $\mathrm{Ca}$ & -4.32 & -0.49 & x 3 & -4.56 & 0.25 & 0.02 \\
\hline & $\mathrm{Eb}$ & -3.65 & -0.69 & x 4 & -4.00 & 0.34 & 0.05 \\
\hline & $\mathrm{Ea}$ & -3.75 & -0.62 & x 176 & -4.06 & 0.31 & -0.04 \\
\hline \multirow[t]{4}{*}{5} & $\mathrm{Cb}$ & -2.14 & -0.65 & x 175 & -2.46 & 0.32 & -0.06 \\
\hline & $\mathrm{Ca}$ & -2.15 & -0.60 & x 177 & -2.45 & 0.30 & -0.03 \\
\hline & $\mathrm{Eb}$ & -2.61 & -0.09 & x 130 & -2.66 & -0.01 & -0.04 \\
\hline & $\mathrm{Ea}$ & -2.72 & -0.23 & x 178 & -2.84 & 0.12 & -0.01 \\
\hline \multirow[t]{4}{*}{6} & $\mathrm{Cb}$ & -5.20 & -0.95 & x 164 & -5.68 & 0.40 & -0.25 \\
\hline & $\mathrm{Ca}$ & -4.86 & -0.79 & × 159 & -5.26 & 0.29 & -0.27 \\
\hline & $\mathrm{Eb}$ & -4.22 & -0.41 & x 175 & -4.42 & 0.20 & -0.04 \\
\hline & $\mathrm{Ea}$ & -4.98 & -1.07 & x 166 & -5.52 & 0.47 & -0.26 \\
\hline
\end{tabular}

\begin{tabular}{|c|c|c|c|c|c|c|c|}
\hline Subiect & Control/experiment & Convent & notation & & Compon & tation & \\
\hline Subject & Control/ experiment & Sph & $C y l$ & Axis & Fst & For & Fob \\
\hline 1 & C & 0.30 & -0.22 & x 107 & 0.18 & -0.09 & -0.06 \\
\hline & $E$ & 0.30 & -0.22 & $\begin{array}{ll}\mathrm{x} 107 \\
\end{array}$ & 0.23 & -0.15 & -0.03 \\
\hline 2 & C & 0.14 & -0.17 & x 3 & 0.05 & 0.08 & 0.01 \\
\hline & E & 0.17 & -0.07 & X 154 & 0.13 & 0.02 & -0.03 \\
\hline 3 & $\mathrm{C}$ & -0.24 & -0.18 & x 110 & -0.33 & -0.07 & -0.06 \\
\hline & E & -0.43 & -0.20 & x 34 & -0.54 & 0.04 & 0.09 \\
\hline 4 & $\mathrm{C}$ & 0.14 & -0.23 & × 159 & 0.03 & 0.08 & -0.08 \\
\hline & E & 0.04 & -0.20 & x 124 & -0.06 & -0.04 & -0.09 \\
\hline 5 & $\mathrm{C}$ & 0.05 & -0.07 & × 66 & 0.01 & -0.02 & 0.03 \\
\hline & $E$ & -0.05 & -0.26 & × 8 & -0.18 & -0.12 & -0.04 \\
\hline 6 & $\mathrm{C}$ & 0.53 & -0.23 & x 94 & 0.42 & -0.11 & -0.01 \\
\hline & $E$ & -0.75 & -0.70 & x 161 & -1.10 & 0.27 & -0.22 \\
\hline
\end{tabular}


myopic shift over the six months with a "downward" movement of both the red and green comets. The green comet is the longer of the two indicating a larger myopic shift for the eye wearing the silicone lens. The means and differences of the measurements can be seen in Tables 3 and 4 .

Figure 4 (subject 4) shows little stigmatic (spherical) change in either eye with most of the change being antistigmatic (put simply, astigmatic). The origin of the plot is $-4.00 \mathrm{D}$. However, the eye wearing the silicone lens did have a myopic shift in refractive state (see Tables 3 and 4) while the habitual lens wearing eye had a small hyperopic shift. The small dots at the end of each comet show the $95 \%$ confidence ellipsoid. Figures 5 (subject 5, origin of axes $-2.00 \mathrm{D}$ ) and 6 (subject 6 , origin of axes $-5.00 \mathrm{D}$ ) both show an increase in myopia in the eyes wearing the silicone hydrogel lenses. Subject 5 shows a -0.18 D stigmatic shift while subject 6 shows a $-1.10 \mathrm{D}$ stigmatic shift (see Tables 3 and 4). Subject 5 reveals almost no shift in the habitual lens wearing eye while subject 6 shows a reduction $(0.42 \mathrm{D})$ in myopia in the eye wearing the habitual lens.

Albeit that the sample is relatively small the mean difference in refractive state for eyes wearing a habitual hydrogel lens is $0.06 \mathbf{I}-0.04 \mathbf{J}-0.04 \mathbf{K}$ $\mathrm{D}$ in component notation while the mean difference in refractive state for eyes wearing the silicone hydrogel lenses is $-0.30 \mathrm{I} \quad 0.06 \mathrm{~J}-0.05 \mathrm{~K} \mathrm{D}$.

\section{Discussion}

Four of the six subjects in this study show an increase in myopia, of varying amounts, in the eye wearing the silicone hydrogel lens on a daily wear basis for six months. Statistically, the changes seen in this study could be purely as a result of chance and have no support, there were too few subjects. The increases in myopia in the four subjects suggest a possibility that eyes wearing silicone hydrogel lenses do in fact show increases in myopia, a finding that is contrary to other studies conducted investigating continuous wear of silicone lenses ${ }^{24-27}$.

An interesting observation during this study was the apparent with drawl of blood from all the neovascular vessels seen prior to the initiation of silicone lens wear. The eyes wearing the habitual lenses did not show any reduction in the blood flow through the neovascular vessels, a finding that has been reported by others. This study needs to be repeated making use of more subjects. It might also be prudent to include a cross-over study design so that the effects of silicone lens wear versus conventional water-based hydrogel lens wear can be investigated more completely. The results should prove interesting.

\section{Acknowledgment}

To Ciba Vision (South Africa) for the donation of Focus ${ }^{\circledR}$ Night and Day ${ }^{\mathrm{TM}}$ contact lenses used in this study.

\section{References}

1. Beresford JA, Crewther SG, Kiely PM, Crewther DP. Comparison of refractive state and circumferential morphology of retina, choroid and sclera in chick models of experimentally induced ametropia. Optom Vis Sci 200178 40-49.

2. Fulk GW, Cyert LA, Parker DA. Seasonal variation in myopia progression and ocular elongation. Optom Vis Sci 200279 46-51.

3. Brown B, Edwards MH, Leung JTM. Is esophoria a factor in slowing of myopa by progressive lenses? Optom Vis Sci 200279 638-642.

4. Fulk GW. Is esophoria a factor in slowing of myopia by progressive lenses? Optom Vis Sci 200380 198199.

5. Walline JJ. Are we nearsighted when it comes to myopia treatment? Eye Contact Lens 200329 S139S142.

6. Leech WM, Cottriall AL, McBrien NA. Pirenzepine prevents form deprivation myopia in a dose dependent manner. Ophthal Physiol Opt 199515 351356.

7. Phillips JR, McBrien NA. Form deprivation myopia: elastic properties of sclera. Ophthal Physiol Opt 199515 357-362.

8. Ciuffreda KJ, Wallis DM. Myopes show increased susceptibility to nearwork aftereffects. Invest $\mathrm{Oph}$ thalmol Vis Sci 199839 1797-1803.

9. McBrien NA, Adams DW. A longitudinal investigation of adult-onset and adult-progression of myopia in an occupational group. Refractive and biometric findings. Invest Ophthalmol Vis Sci 199738 321333.

10. Saw SM, Nieto FJ, Katz J. Reading, writing and myopia progression in Singapore children. Invest Ophthalmol Vis Sci 199940 S593.

11. Edwards MH. Effect of parental myopia in the de- 
velopment of myopia in Hong Kong Chinese. Ophthal Physiol Opt 199818 477-483.

12. Harris MG, Sarver MD, Polse KA. Corneal curvature and refractive error changes associated with wearing hydrogel contact lenses. Am J Optom Physiol Opt 197552 313-319.

13. Hill JF. A comparison of refractive and keratometric changes during adaptation to flexible and nonflexible contact lenses. J Am Optom Assoc 197546 290-294.

14. Barnett WA, Rengstorff RH. Adaptation to hydrogel contact lenses: variations in myopia and corneal curvature measurements. J Am Optom Assoc 197748 363-366.

15. Rengstroff RH, Nilsson KT. Long-term effects of extended wear lenses: changes in refraction, corneal curvature and VA. Am J Optom Physiol Opt 198562 66-68.

16. Hill JF. Variation in refractive error and corneal curvature after wearing ultra-thin hydrophyllic contact lenses. Int Contact Lens Clin 1976 3 23-29.

17. Miller JP, Coon LJ, Meier RF. Extended wear of Hydrocurve II soft contact lenses. J Am Optom AsSOC $198051225-230$.

18. Binder PS. Myopic extended wear with the Hydrocurve II soft contact lens. Ophthalmol $1983 \mathbf{9 0}$ 623-626.

19. Fulk GW, Cyert LA, Parker DE, West RW. The effect of changing from glasses to soft contact lenses on myopia progression in adolescents. Ophthal Physiol Opt 200323 71-77.

20. Douthwaite WA, Ford MW, Francis JL, Stone J. Practical optics and computer design of contact lenses. In: Phillips AJ, Stone J, ed. Contact lenses: third ed. Somerset: Butterworths. 1989:225.

21. Bruce AS, Brennan NA. Corneal pathophysiology with contact lens wear. Surv Ophthalmol 199035 25.

22. Efron N, Fitzgerald JP. Distribution of oxygen across the surface of the human cornea during soft contact lens wear. Optom Vis Sci 199673 659-665.

23. Gillan WDH. Soft lens induced myopia: does it exist? S Afr Optom $1990 \mathbf{5 0} 83$.

24. Dumbleton KA, Chalmers RL, Richter DB et al. Changes in myopic refractive error with nine months' extended wear of hydrogel lenses with high and low oxygen permeability. Optom Vis Sci 199976 845-849.

25. Long B, Malet F, Lejeune M, George-Vicariot MN, Pagot R, Peyre C, Subirana X. Three year followup of biomicroscopy signs and refractive status in patients wearing Lotrafilcon A lenses. Eye and Contact Lens 200531 263-267.

26. Fonn D, MacDonald KE, Richter D, Pritchard N. The ocular response to extended wear of a high
Dk silicone hydrogel contact lens. Clin Exp Optom 200285 176-182.

27. Jalbert I, Stretton S, Naduvilath T, Holden B, Keay L, Sweeney D. Changes in myopia with low-Dk hydrogel and high-Dk silicone hydrogel extended wear. Optom Vis Sci 200481 591-596.

28. Bullimore MA, Fusaro RE, Adams GW. The repeatability of automated and clinical refraction. Optom Vis Sci 199875 617-622.

29. Perrigin DM, Grosvenor T, Perrigin J. Comparison of refractive findings obtained by the Bausch and Lomb IVEX and conventional clinical refraction. Am J Optom Physiol Opt 198562 562-567.

30. Grosvenor T, Perrigin DM, Perrigin J. Comparison of American optical SR-IV refractive data with clinical refraction data on a group of myopic children. Am J Optom Physiol Opt 198360 224-235.

31. McBrien NA, Millodot M. Clinical evaluation of the Canon R-1 autorefractor. Am J Optom Physiol Opt 198562 786-792.

32. Blackie CA, Harris WF. Refraction and keratometry: departures from and transformations toward multivariate normality. Optom Vis Sci 199774 452458.

33. Cronje S, Harris WF. Short-term keratometric variation in the human eye. Optom Vis Sci 199774 420-424.

34. Rubin A, Harris WF. Refractive variation during autorefraction: multivariate distribution of refractive status. Optom Vis Sci 199572 403-410.

35. MacKenzie GE, Harris WF, Van Gool RD. Comparison of first-order schematic eyes in 20-dimensional inner-product space. S Afr Optom 200463 103-108.

36. Van Gool RD, Harris WF. The concept of the average eye. S Afr Optom 200564 38-43.

37. Gillan WDH, Harris WF. Dark refraction shift with allowance for astigmatism. S Afr Optom 200564 26-30.

38. Harris WF. Algebra of sphero-cylinders and refractive errors, and their means, variance and standard deviation. Am J Optom Physiol Opt 198865 794802.

39. Harris WF. Mean of a sample of equivalent dioptric powers. Optom Vis Sci 199067 359-60.

40. Harris WF. Statistical inference on mean dioptric power hypothesis testing and confidence regions. Ophthal Physiol Opt 199010 363-372.

41. Harris WF. Dioptric power its nature and its representation in three-dimensional space. Optom Vis Sci 199774 349-366.

42. Harris WF. Analysis of astigmatism an anterior segment surgery. J Cataract Refract Surg 200127 107-128. 